\title{
Refractory Malignant Thyroid Gland Neoplasm
}

National Cancer Institute

\section{Source}

National Cancer Institute. Refractory Malignant Thyroid Gland Neoplasm. NCI

Thesaurus. Code C150539.

Malignant thyroid gland neoplasm that is resistant to treatment. 